\title{
Contextualized Metrics + Narrating Binaries: Defining Place and Process in Indigenous North America
}

\author{
WANDA DALLA COSTA \\ Arizona State University
}

This paper introduces four cultural catalysts in Indigenous architecture: language, place, kinship and transformation. Inspired by the interrelationship of physical, sociocultural and spiritual factors - the measurable and immeasurable - we investigate a number of concepts related to Indigenous thinking and ways of knowing. We contrast these notions with non-Indigenous writers including Pallasmaa, Ricoeur and Doshi, in the hopes of initiating a dialogue, and assisting the two-way knowledge transfer, between architecture and Indigenous theory.

\section{INTRODUCTION}

In 2015, a Blackfoot ceremonialist, Reg Crowshoe lectured on cultural protocol when working with indigenous people. He was talking about the theoretical space that exists between western and indigenous worldviews. He tells the story about growing up within an indigenous worldview. While at boarding school, he became challenged. He started mixing the science and math principles from his oral tradition, with western principles. Years later, sharing his story with Elders, they told him he was experiencing cultural confusion, or trying to find answers from mixing both cultures together. The Elders advised him to pull the cultures apart and find parallel meanings. Those meanings, they said, are the best place to move forward. ${ }^{1}$

This paper argues, that in order to find parallel meanings in architecture, we need to begin a dialogue. Architects work within contextual influences including the history of people and place, but they are also influenced by current discourse, familiar methodologies, and their own underlying epistemologies. This paper seeks to facilitate a two-way knowledge transfer. The theoretical context is a blend, incorporating Indigenous theory from multiple disciplines, with comparative non-Indigenous theory. We contrast writers such as Pallasmaa, Ricoeur, Doshi and Mumford against a backdrop of indigenous scholars including Cajete, Jojola, Smith and Matunga.

Throughout this discussion, bear in mind, that indigenous theory is always in transformation. As Matunga states, "Indigenous communities continue to contextualize traditional knowledge across a range of diverse and previously unpredicted settings." ${ }^{2}$ Architecture should not be the exception.

A note on the word Indigenous. Referring to Indigenous as a collective is not intended to disregard diversity. There is unity among global Indigenous populations, due to similar circumstances and aims. The term Indigenous is taken from the United Nations definition, and used to refer to a group of people who "resolve to maintain and reproduce their ancestral environments and systems as distinctive people and communities." 3 Future consideration in this subject, should move from general concepts as introduced in this paper, to culturally- and regionally- specific analysis.

\section{THE LANGUAGE OF BLENDED KNOWLEDGES}

Indian people are people of place, and the nature of place is embedded in language. ${ }^{4}$

While planning of the built environment is not a new concept to tribal people, creating the spoken and visual language that can respond to the myriad of situations that these societies are finding themselves in, is new. Our task in defining Indigenous architecture, is to work on both the spoken and visual languages, as complementary forms of communication. This section argues that we must begin to investigate the process of translation that takes place between the architect and the users.

Chris Cornelius is an Oneida architect whose research is focused on the architectural translation of culture. During his involvement in the Indian Community School, he produced a number of cultural translation diagrams (refer to Figure 4). The Cultural Values Network Diagram captures values. The Cultural Laminate Process Diagram captures associations of spoken language. Together, these diagrams reflect a process, a way of working, perhaps personal, perhaps portable, but a toolset in deciphering the multi-layered materiality and memory within Indigenous built environments.

To some, Cornelius's attempt to explicate community values in an associative diagram of words carries with it the danger of overabundance to the point of becoming architecturally irrelevant. To others, the diagrams investigate needlessly the curation or artistic process within architecture. While still to others, these diagrams may assist in 


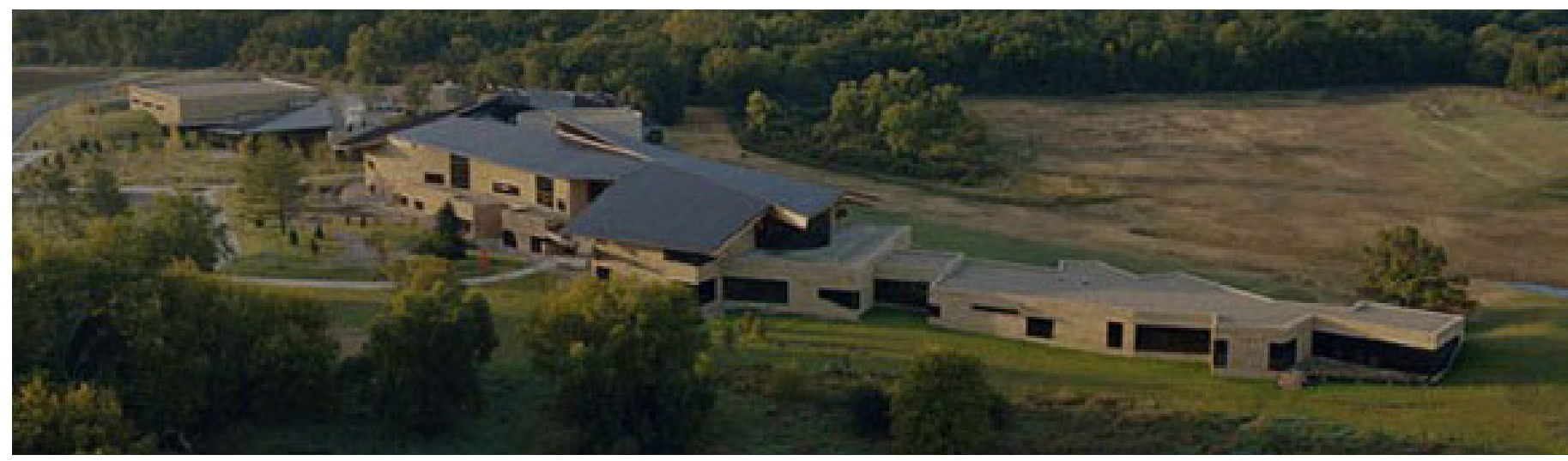

Figure 1: Antoine Predock Architect with Chris Cornelius, Indian Community School of Milwaukee.

deciphering the cultural resources of a nation, pushing towards the 'creative nucleus of mankind.' ${ }^{5}$ Still yet, there may be some viewers, who see Cornelius's process as a reminder of the power of reflexivity (or self) in the creation of architecture.

\section{PLACE-BASED + STORIED LANDSCAPES}

Places are imbued with spirit and are our teachers. As tribal people, there is an understanding of how to proceed based upon a long history of interrelationship with a particular territory. ${ }^{6}$

Designing for indigenous societies is designing within a highly contextualized realm. Indigenous people, their territories, and the knowledge that emerges from place, is highly intertwined. Malnar and Vodvarka reference Edward T. Hall who discusses high- and low-context messaging. High context messaging is the result of an abundance of "information.. inherent in the physical conditions." 7 Low-context messages, on the other hand, require explicit codes to account for every exigency. Two principles from indigenous science will assist in this discussion, Relational Worldview and Metaphoric Mind.

According to Gregory Cajete, the author of Native Science, humans are one of many life forms in the natural world, influencing each other and being influenced in return. The process is called the Relational Worldview. According to Cajete, this is the fundamental distinction between indigenous and western thinking. The Relational Worldview has resulted in the prioritization of direct, perceptual experience, echoing the central premise of phenomenology. ${ }^{8}$

A similar concept is illuminated by Pallasmaa. In writing on the Constituents of Locality, he states that in order to avoid "sentimental scenography...a naively shallow architectural souvenir," culture has to be lived. An authentically culturally differentiated architecture can only be born from differentiated patterns of culture," and this includes "expressions and experiences of specific nature, geography, landscape." 9

Pallasmaa questions if we have access to the conditions which create an authentically culturally differentiated architecture. In fact, we have, but we must know where to begin. Cajete reveals the access point as the Metaphoric Mind. ${ }^{10}$ Active in early learning, this mind is tied to creativity, perception, image, imagination, physical senses, and intuition. It reveals itself through sound, holistic ecological thinking, abstract symbols, kinesthetic expression, visual-spatial reasoning, linguistic metaphors and oral stories, and accordingly, affects art, music, dance, and arguably architecture. In western society, scientific rationalism elevates the rational mind over the Metaphoric Mind. Native societies instead, prefer to balance the two, accessing more holistic structures of knowledge.

To provide an example, we look to the image of a turtle. A turtle is an encoded metaphor used to depict the relationship to place. Found in many creation stories, the turtle represents, among other things, the underworld or earth that carries all the processes of the earth, "a metaphor whose meaning is contexted in myth, experience (and) understanding." ${ }^{11}$ Symbols, in this case the turtle, are then carried into stories, and the stories become the libraries of place. As Jay Johnson writes, "each story is a text within the metanarrative of a particular culture." 12

The workings of holistic structures of knowledge, illuminated by Cajete and Johnson, also illustrate the challenges inherent in the spatial design of indigenous environments. The level of immersion of a westerntrained architect during the design phase of an architectural project in indigenous communities is limited. Architectural product is the result of both methodology and epistemology. Viewed in this way, it is easy to see why Graham Smith postulates certain requirements for Indigenous theory, one of which is that it is the "product of a theorist who has an understanding of the cultural epistemic foundations of an indigenous worldview." 13

While this section offers more challenges than solutions, a recent study in a related field offers a spark of insight. Robinson and Lane recently completed research on Indigenous knowledge contributions to natural resource decision making in Australia. ${ }^{14}$ The term Boundary Agents or Knowledge Brokers refers to the locals who act as bridges between formal and informal institutions and networks. These agents have a keen perception of place. Their knowledge is viewed as parallel to the external, or expert, perspectives. In architecture, this is fulfilled by Elders and/or Cultural Advisors. These brokers are our closest allies in architecture, carrying with them the ability to access latent materiality and memory. Brokers bring a high context way of life into an operational format. 


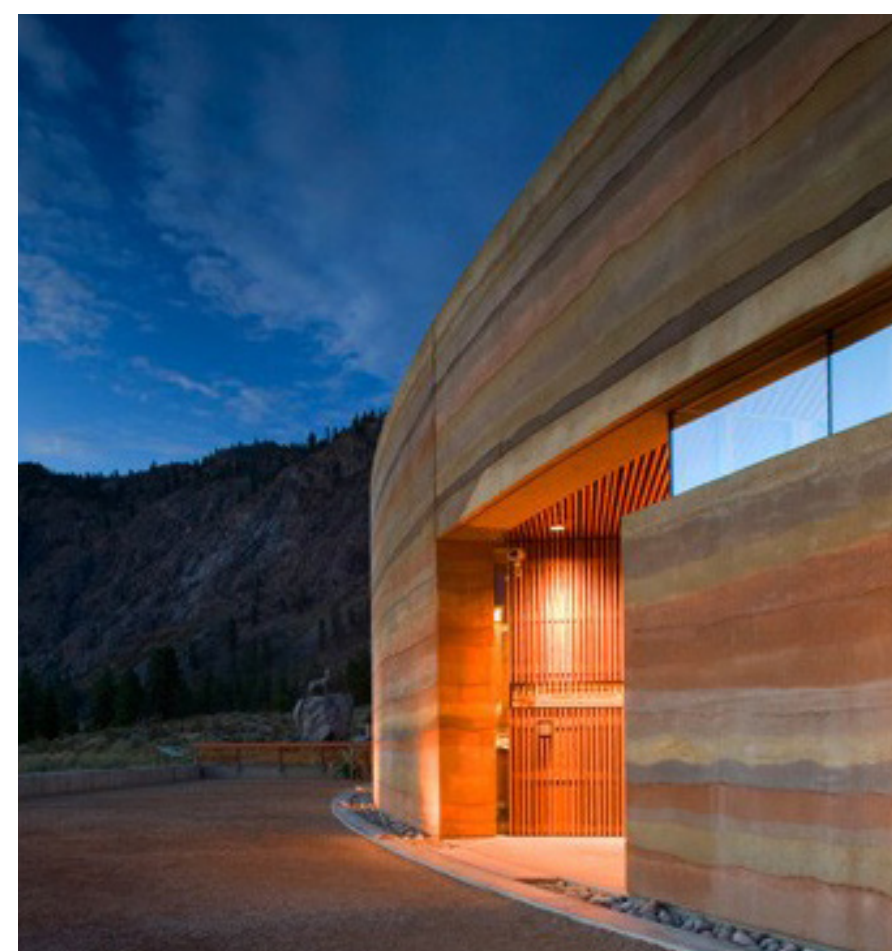

Figure 2: Dialog, Nk'Mip Desert Cultural Centre (Osoyoos Indian Band).

\section{COMMUNITY, KINSHIP + EXPANDED METRICS}

This section explores another cultural catalyst in architecture. We move from the influence of place, to the notion of kinship-based societies. Due to the fact that successive generations reside in a geographically limited community, such as a reservation, physical development is but one part of a larger network of forces. An expanded value-based analysis, which includes the economic, social, cultural and environmental is required. Our questions: How can we as architects, access this information? Can it be translated into a format useful for future practice?

We start with a quote from Balkrishna Doshi on the power of culture and community in the creation of built environments:

In traditional Indian society, one is not alone, but part of a community. Buildings are not built in isolation, but in groups leading to a total environment, merging buildings, spaces, and culture in a unified whole. The community shares everything.... Unless this socio-cultural tradition is understood, the organization of buildings, streets, spaces and their forms cannot be the desired fabric wherein the community wants to live. It is, therefore, necessary to talk about physical environment in terms of culture rather than only in terms of buildings, space, technology or economy. ${ }^{15}$

At the same time, we are cognizant of Malnar and Vodvarka's recent declaration, that the implicit design sensitivities within Indigenous culture, result in an architecture that is "more complex, profound and meaningful than current western practice." 16 Pallasmaa would agree, arguing that buildings of the post-modern era accelerated estrangement and alienation, and as a result, we are looking for answers in the "unique and authentic forms of indigenous and vernacular traditions." ${ }^{17}$
But where are the answers to be found? Paul Ricoeur in writing about the conflicts between the process of global modernization and the identity of regional cultures, tells us where they are not found: in the intellectualization of cultural meaning. Ricoeur cautions us on searching solely within the rational and reflective, and advises us to move to a "much lower level", toward attitudes and values embedded in life: "those concerning tradition, change, our behavior toward our fellowcitizens and foreigners, and...the use of available tools." 18

Accessing cultural meaning in built environments is the goal of Hirin Matunga, an Indigenous Planner from New Zealand. He argues that the greatest challenge for spatial planners in creating indigenous environments is "facilitating a more nuanced reading of its multi-layered materiality and memory through architecture, urban design and environmental management." ${ }^{19}$ By materiality he is referring to the physical quality, presence and structure; by memory he is referring to the recall of experience and existence. Matunga tells us where to find answers. He states that spatial planners must go back to the spatial knowledge found within traditional cultures.

According to Matunga, the link between ancestral places and the inhabitants, is provided for through the process of planning. All the biological, spatial, cultural, social, economic, and political factors which have the potential to impact the spatial environment, are accounted for. Decisions are highly contextual to that community, and are located within its worldview and value systems. The six elements of his proposed Indigenous Planning as Process are: People, Place, Knowledge, Worldview and Values, Decisions and Practice. If we are aiming, for what Pallasmaa refers to as a differentiated architecture born from a differentiated pattern of culture, it seems we must immerse ourselves, as Matunga does, in all factors potentially impacting the built environment.

Balkrisha Doshi elaborates on the notion of process in architecture. He refers to the set of interrelated socio-cultural, physical and spiritual factors. Together they account for "centuries of learning with regard to orientation, climate, building materials and construction techniques," the "order and models for relationships between families, communities, cities and regions" and "total harmony with the life-style in all its daily and seasonal rituals." 20

What we see through Ricoeur, Matunga, Pallasmaa and Doshi is that the cultural continuum of context is a considerable responsibility, and one that must balance the individual and the collective. In the best case scenario, the autonomous (artistic) nature of architecture and the culture-bound nature of this endeavor, is complementary. Artistic pursuits and the socio-cultural institutions affecting architecture "are locked into a dynamic relationship nurturing and complementing each other." 21

In the worst case scenario, we as architects are overloaded with the immensity of the task. If we are to incorporate even a fraction of what Matunga, Pallasmaa and Ricoeur propose - the latent materiality and memory; conscious and unconscious; memories, and experiences; the individual and collective; attitudes and values - we become paralyzed. Earlier, we offered the notion of Boundary Rider to bridge 


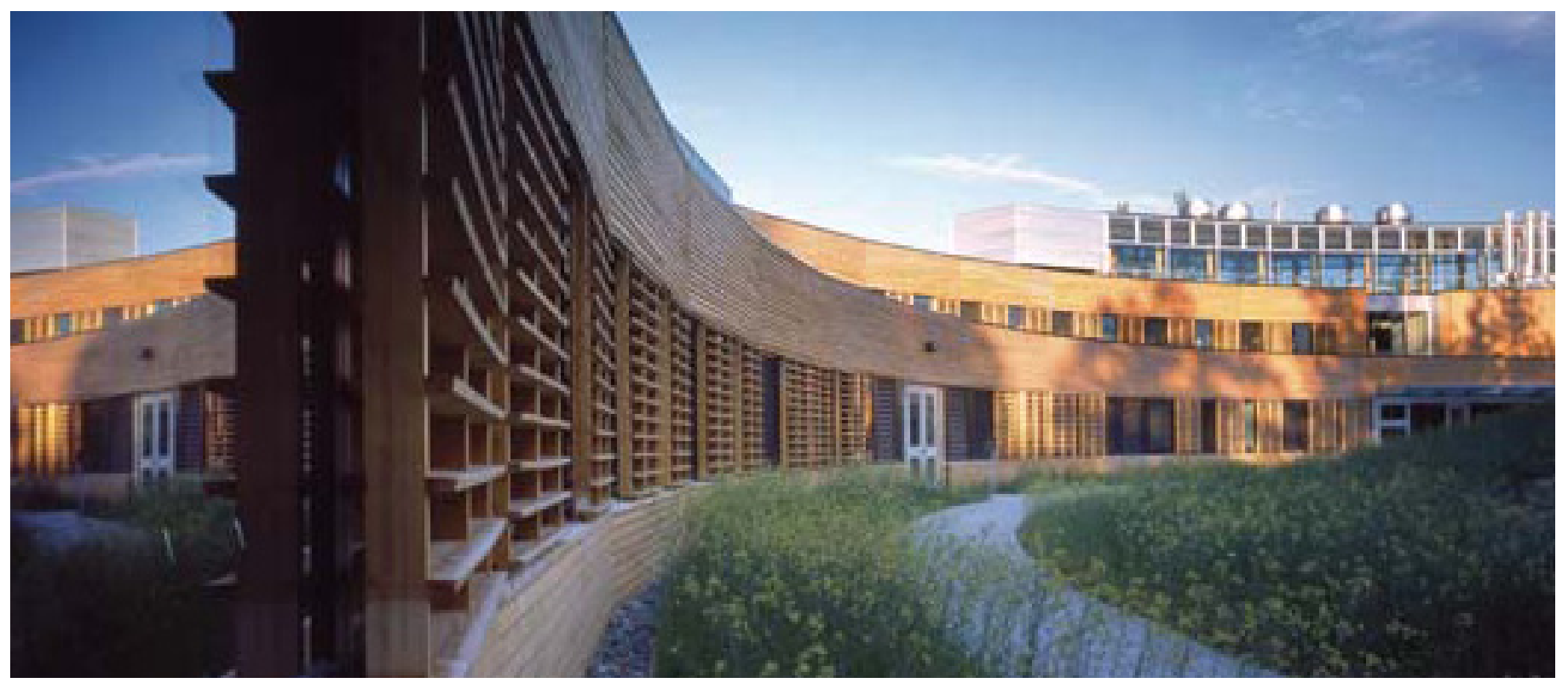

Figure 3: Perkins + Will with Alfred Waugh, Nicola Valley Institute of Technology, University College of the Cariboo.

Indigenous place-based knowledge. Here, we present for discussion, an Indigenous Metric-Matrix to assist with the multivalent variables inherent in Indigenous spatial design.

Indigenous societies based their knowledges in detailed oral codes of collective living. The question is: Can we formalize this, in order to nurture the complementary relationship between art and the socio-cultural institutions of the built environment? Ted Jojola, a distinguished professor of architecture and planning at University of New Mexico, believes it is required, asserting: "the incorporation of cultural information into a format that can be used for planning is critical." 22 Is this desirable or attainable in architecture?

One attempt was made by Kenza Boussora, who studied Algerian architecture and declared its short comings: climatically, spatially, economically and culturally. ${ }^{23}$ To address the gap between the theoretical objectives and achievement in practice, Boussora created an inventory of meanings to guide regional building and contextualize cultural architecture. ${ }^{24}$ Boussora proposed an inventory of nine elements which include more conventional analysis, such as architectural heritage and life-style surveys that define patterns of activity. He also proposed non-conventional, highly contextual notions, such as the economics of available labor and material, and an assessment of training for the development of new skills.

Perhaps Boussora's inventory can be the starting point for a MetricMatrix in Indigenous architecture. It goes without saying, there are a number of challenges inherent in an inventory process. First, is creating meaning for the 1,184 diverse tribal cultures in North America. A second challenge is decoding oral narrative, symbols and embedded place-based histories. Entrenched within decoding, comes a subset of responsibilities which include prioritizing values, negotiating binaries inherent in contemporary indigenous design and articulating a process of translation that may (or may not) be portable, such as the work of Cornelius. Nonetheless, the impending loss of cultural traditions with each passing generation, calls for a new mode of thinking that can swiftly bind western and indigenous knowledges in architecture.

\section{TRANSFORMATIVE}

Miyo is the Cree word for 'good,' a simple word but one that drives behavior within Cree societies. Miyo describes "a way of being which encompasses values critical for collective living including sharing, generosity, respecting the earth, good relations, collective responsibility and stewardship." 25 Pallasmaa tells us that language itself can be used to generate architecture, referring to Alvar Aalto's amorphous forest geometry, a result of Finnish tendencies stemming from language. The word Miyo, and its embedded meanings illustrate the potential of language in acting as one of many hidden dimensions in the culturally conditioning of spaces.

According to Graham Smith, a vital requirement of Indigenous theory, is its transformative ability, "where the research gives back to and benefits the community in some manner." ${ }^{26}$ Matunga echoes this goal, introducing the notion of Indigenous Planning as Outcome. He outlines five critical aims of planning, all of which contribute to community well-being: Cultural Protection and Enhancement; Social Cohesion and Well-Being; Environmental Quality and Quantity; Economic Growth and Distribution; and Political Autonomy and Advocacy. All of these become potential indices, towards a MetricMatrix in measuring the success of the built environment in Indigenous communities.

In looking for specific examples of transformative architecture, we look to Alfred Waugh, a Canadian architect from the Fond du Lac First Nation. Waugh developed a way of working in architecture which begins to address the language of transformation. Working from the precedent of the long house, he extrapolates traditional architecture principles, such as natural ventilation found in traditional forms, or tectonic connections articulated by post and beam structures, and 

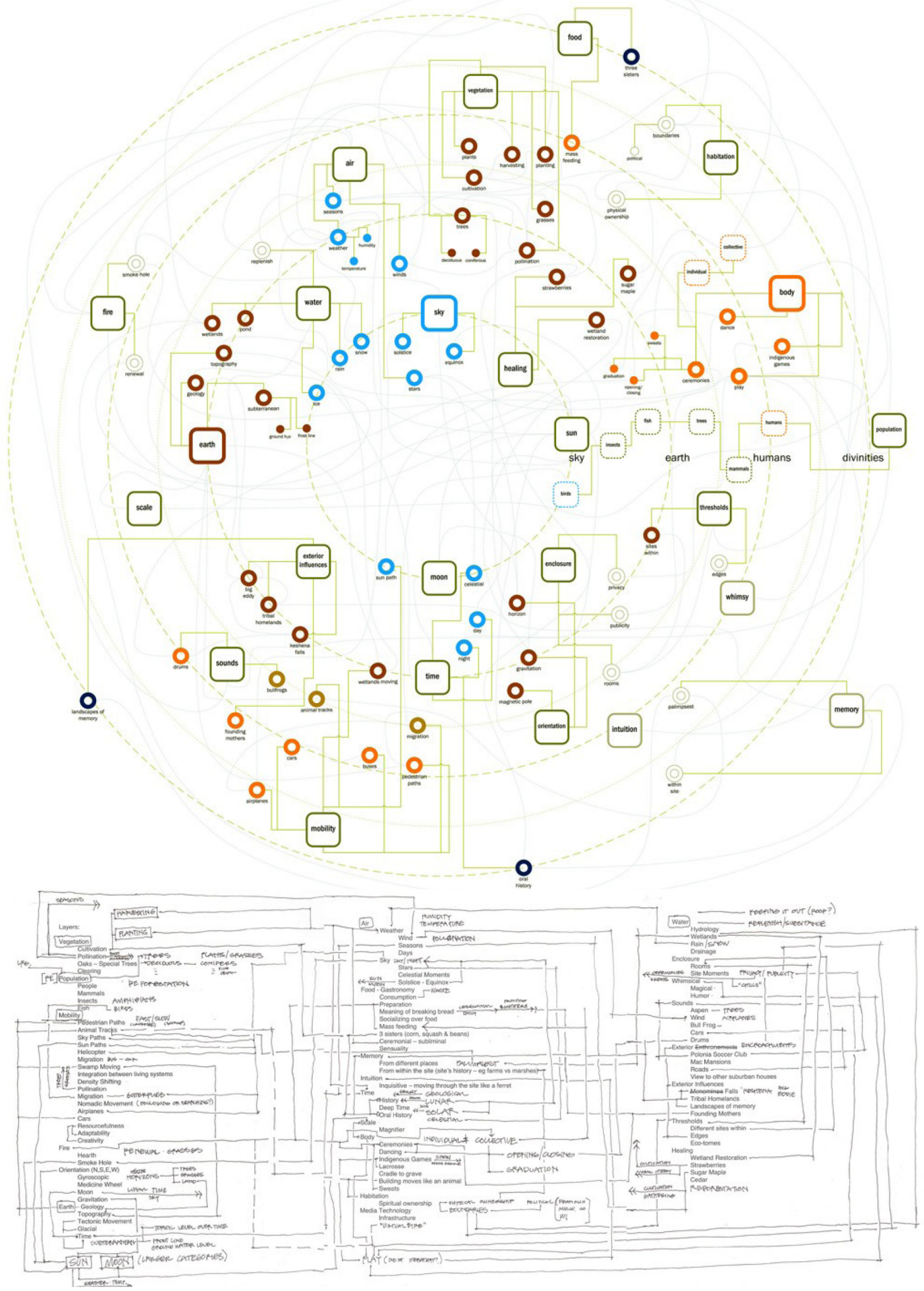

Figure 4: Chris Cornelius, Cultural Values Network Diagram (top); Cultural Laminate Process Diagram (bottom) 
uses these as progenitors of contemporary technical methods. ${ }^{27}$ Contemporary manipulation without loss in meaning. The exogenous and the endogenous.

One final thought on the transformative potential of architecture, and that is the concept of Design Thinking. The concept is currently being used by companies such as Apple and Herman Miller to improve the look, functionality and performance of products through understanding client needs. ${ }^{28}$ It is centered on creating a critical feedback loop through a three-part process: Inspiration, Ideation and Implementation.

Phase one is Inspiration, or defining the problem or opportunity that motivates the search for a solution. Applying this to architecture, there is no shortage of Inspiration in Indigenous cultures to draw upon. Worldwide there are 370 million Indigenous people, found in 70 countries, each hosting their own versions of Miyo. In the USA alone, we have 567 distinct federally recognized tribes. Phase two is Ideation, or the generation and testing of ideas. Unfortunately, with very few Indigenous professionals in the field of architecture, the design of the built environment has largely been created using Eurocentric models and methods. Solutions are not measurable, as there is no metric from which to measure success. Phase three is Implementation, or the path that leads into people's lives. We pose the question: has the architecture that leads into the lives of indigenous people been built?

\section{CONCLUSION}

The land-based nature of tribal societies of North America, are highly contextualized and offer distinct conceptions of place. Moreover, the community-based focus necessitates a process-orientated, valuebased and transformative approach to practice. The distinctive context and culture of tribal communities derails universal or global instruments, exposing innovative design methodologies that speak to diversity and its associated expanded value systems.

There are many tasks in the search for parallel meanings in architecture, but we propose two critical tasks to begin. First we must focus on Ideation, or creating a feedback loop in Indigenous architecture. Once we broaden the metrics by which we measure success in the built environment, sourcing parallel meanings, evoking high-context solutions, and tuning into community-driven concepts such as Miyo, the language, both spoken and visual, will emerge.

Second, we need to embark on a process of reflexivity. The influence of self, forms a vital part of Indigenous Methodologies, yet it is often down played in the profession of architecture. Once we attain reflexivity, we have the capacity to activate higher perceptions. As Ricoeur states, "human truth lies only in this process in which civilizations confront each other more and more with what is most living and creative in them. ...each civilization will work out its perception of the world by confronting all others." 29

\section{ENDNOTES}

1. Reg Crowshoe and Willie Ermine, "Ethical Spaces: Elder Reg Crowshoe and Elder Willie Ermine," accessed May 31, 2016, https://vimeo.com/112213678.

2. Matunga, Hirin, "Theorizing Indigenous Planning" in Reclaiming Indigenous Planning, ed. Ryan Walker, Theodore S. Jojola, David C. Natcher (Montreal: McGillQueen's University Press, 2013), 17.

3. "Who are Indigenous People?" A fact sheet by United Nations. Found at http:// www.un.org/esa/socdev/unpfii/documents/5session_factsheet1.pdf

4. Cajete, Gregory, Native Science: Natural Laws of Interdependence (Clear Light Publishers, Santa Fe, NM, 2016): 74.

5. Ricoeur, Paul, "Universal Civilization and National Culture" in Canizaro, Vincent B. Architectural Regionalism: Collected Writings on Place, Identity, Modernity, and Tradition. New York, US: Princeton Architectural Press, 2006. ProQuest ebrary. Web. 28 July 2016, 47-51.

6. Cajete, 42

7. Malnar, Joy M, and Frank Vodvarka. New Architecture on Indigenous Lands (University of Minnesota Press, Minneapolis, MN, 2013): 8.

8. Cajete, 23

9. Ibid, 131.

10. Cajete, 24

11. Ibid, 51 .

12. Johnson, Jay T., "Place-based Learning and Knowing: Critical Pedagogies Grounded in Indigeneity," GeoJournal 77, no. 6 (2012): 833.

13. Kovach, 46.

14. Robinson, C., \& Lane, M. "Boundary-Riding: Indigenous Knowledge Contributions for Natural Resource Decision Making in Northern Australian Regions" In R. Walker, T. Jojola, \& D. Natcher (Eds.), Reclaiming Indigenous Planning (pp. 396-413). McGill-Queen's University Press, 2016, 397.

15. Doshi, Balkrishna, "Cultural Continuum and Regional Identity in Architecture," in Vincent B., 114.

16. Malnar and Vodvarka, 3.

17. Pallasmaa, 130

18. Ricoeur, 49.

19. Matunga, 9 .

20. Doshi, 111-114.

21. Ibid, 111.

22. Jojola, Ted. "Indigenous Planning: Towards a Seven Generations Model" in R. Walker, T. Jojola, \& D. Natcher (Eds.), Reclaiming Indigenous Planning (pp. 396-413). McGill-Queen's University Press, 2016, 352.

23. Boussora, Kenza, "Regionalism: Lessons from Algeria and the Middle East" in Vincent B., 1990, 127-128.

24. The four main objectives of regionalism: building in harmony with social needs, local resources, geographical characteristics and existing built form.

25. Kovach, 63.

26. Ibid, 91 .

27. Malnar \& Vodvarka, 54.

28. Brown, Tim and Jocelyn Wyatt. "Design Thinking for Social Innovation." Stanford Social Innovation Review (Winter 2010): 32, accessed May 31, 2016, https://www. ssireview.com. 31-35.

29. Ricoeur, 53. 